\title{
Head and neck cancer in Africa
}

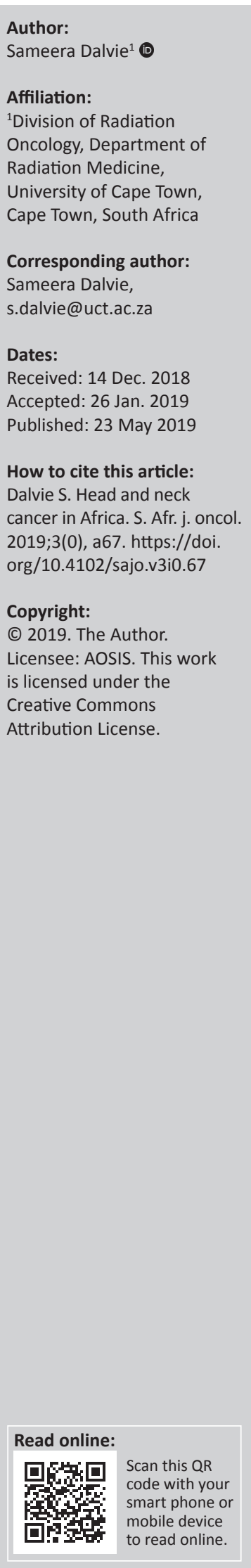

Background: Head and neck cancer is the sixth most common cancer globally. Therapy is complex. Most patients present with locally advanced disease. Management is a combination of surgery, chemotherapy and radiotherapy. Published guidelines are available for the developed world, but there are no official guidelines for Africa.

Aim: The aim of the survey was to describe diagnosis and management of head and neck cancer in Africa.

Setting: This study was undertaken by a clinical oncologist employed by the state sector in South Africa.

Methods: An online, cross-sectional electronic survey was mailed to oncologists and surgeons, working in the field of head and neck cancer in Africa. The survey was open from August 2016 to January 2017. Questions were posed about diagnosis and management.

Results: Thirty-nine respondents from different locations in Africa responded. All the respondents practised in urban centres in their respective countries. Sixty-three per cent identified as oncologists. The remainder identified as surgeons. A third of the respondents see more than 200 head and neck patients per year. Access to diagnostic tools as well as therapy resources was limited. Forty per cent of the patients were assessed in a multidisciplinary clinic. Surgery and adjuvant radiotherapy are important modes of therapy, in the setting of locally advanced disease. Two-dimensional radiotherapy and clinical mark-up were utilised by $47 \%$ and $34 \%$ of respondents, respectively. A substantial proportion of patients with curative disease were treated palliatively.

Conclusion: Trainers from well-established centres in Africa need to develop coordinated training programmes to facilitate the establishment of multidisciplinary teams. This will aid in the development of local, relevant protocols.

Keywords: clinical oncology; head and neck surgery; Africa; management; resources; multidisciplinary team; guidelines.

\section{Background}

Head and neck cancer is the collective term for a group of tumours that arise in the head and neck area. It defines a heterogeneous group of cancers. Therapy is often individualised, as it must be tailored to the patient, tumour and available resources. ${ }^{1}$ There are published guidelines in the developed world for diagnosis and management., ${ }^{2,3}$ These guidelines are accepted as gold standard therapy. There is a paucity of literature referencing guidelines that are applicable to management in low- to middle-income countries. ${ }^{5}$ It is widely recognised that Africa is a diverse continent, with a gamut of resources. Sub-Saharan Africa has a significant cancer burden. ${ }^{6}$ The region has many socio-economic challenges including political instability, lack of infrastructure and low resources. Presentation at an advanced stage of disease is well documented in the literature. ${ }^{6,7,8}$ An online survey was undertaken to describe the diagnosis and management of head and neck cancer in African countries.

\section{Materials and methods}

An online, cross-sectional electronic survey was mailed to oncologists and surgeons, working in the field of head and neck cancer in Africa. The survey was open from August 2016 to January 2017. The mailing list was a synthesis of the members of the African Head and Neck Society, personal contacts as well as the listed contacts of the World Health Organization (WHO) health desk. Questions touched upon aspects of diagnosis, management and supportive care. Thirty questions were posed. They were divided into seven main sections dealing with the physician and their practice, diagnosis, multidisciplinary management, general management, chemotherapy/ biological therapy and palliation. The respondents provided informed consent. Each respondent 
was given the option of answering only those questions that were pertinent to their practice.

\section{Ethical considerations}

Ethical approval was granted by the Human Research Ethics committee of the Faculty of Health Sciences, University of Cape Town (HREC Ref: 770/2016).

\section{Results}

\section{Information about responders}

Of the 115 questionnaires mailed, 39 (33.9\%) responses were received. Most of the responses were received from South Africa and Nigeria with 11 (28\%) and eight (20\%) respondents, respectively. There were three (8\%) respondents each from Ghana and Kenya. There were two (5\%) respondents each from Zimbabwe and Sudan. There was one respondent each from Senegal, Rwanda, Malawi, Guinea, Egypt, Cameroon, Botswana, Zambia, Uganda and Tanzania. All the respondents practised in urban centres in their country. Sixty-three per cent of the respondents identified as oncologists - either clinical or radiation oncologists. The remaining respondents, except a general surgeon, identified themselves as either ear, nose and throat or head and neck surgeons. Seventy-six per cent of the respondents are based at government/academic hospitals. The remainder practised at either privately insured/selffunded hospitals solely or a combination of academic, government and self-funded hospitals. Eighty-seven per cent of respondents (34/39) see more than 50 head and neck cancer patients per year. Twelve $(30.8 \%)$ of these physicians see more than 200 patients per year.

\section{Diagnostics}

Pathology specimens originating from the oropharynx are tested for human papilloma virus (HPV) in 6/36 (16.7\%) of the respondents. Fifty per cent $(18 / 36)$ do not test for HPV. The remainder do not have access either owing to departmental restrictions or require self-funding. Pathology specimens originating in the nasopharynx are tested for Ebstein-Barr virus in 2/35 (5.7\%) of the respondents. Nineteen $(54.3 \%)$ do not have access. The rest have restrictions in place or require self-funding.

Human immunodeficiency virus (HIV) testing is freely available for $27 / 36(75 \%)$ of the respondents. One respondent $(2.8 \%)$ did not have access. The remainder tested for HIV selectively. Computed tomography (CT) scans are freely available for $54.3 \%$ (19/35) of the respondents. One respondent was not able to access CT scans. The remainder could only utilise CT scans for selected or self-funded patients. Magnetic resonance imaging (MRI) was available to $27.8 \%(10 / 36)$ of the respondents. One respondent did not have access to MRI scans. Photon emission tomography-computed tomography is available to $11 \%$ of the patients.

\section{Multidisciplinary management}

Forty per cent $(14 / 36)$ of the responders assess all their patients in a multidisciplinary team. Forty-one per cent $(15 / 36)$ can assess selected patients in a multidisciplinary setting. Nineteen per cent $(7 / 36)$ do not have access to a multidisciplinary team. Speech and hearing therapists are available to $25 \%(9 / 36)$ of the respondents. The remainder have either selected access or no access. Dieticians are freely available to $55.6 \%(20 / 36)$. The remainder have selected or no access to dieticians. Fifty per cent $(18 / 36)$ have access to social workers. The remainder have selected or no access.

\section{Approach to treatments}

Seventy-five (27/36) and seventy-two (26/36) per cent of the respondents chose curative intent surgery or radiotherapy, respectively, as management options for patients diagnosed with early, T1 squamous carcinoma of the tongue who are medically fit. Radiotherapy was defined as external beam radiotherapy. Two respondents had brachytherapy available. Surgery included wide local excision with or without neck dissection. Supportive care and palliative chemotherapy were also chosen as options in 36\% (13/36) and 44\% (16/36) of physicians respectively.

Eighty-nine per cent (32/36) of the respondents chose external beam radiotherapy as a management option for T1 and T2 glottic carcinoma. Surgery, which included supracricoid laryngectomy as well as transoral resection, was chosen as a possible management option by $47 \%(17 / 36)$ and $19 \%(7 / 36)$ of respondents, respectively. Palliative care and palliative chemotherapy were chosen as options by $31 \%$ $(11 / 36)$ and $39 \%(14 / 36)$ of physicians, respectively.

When managing fit patients with locally advanced cancers (T3 and T4), options chosen included induction chemotherapy with chemoradiation (75\%). Surgery and adjuvant radiotherapy were chosen by $67 \%(24 / 36)$ of the respondents. Chemoradiation alone was chosen by $64 \%$ (23/36) of the respondents. Surgery as a sole modality of therapy was utilised by $19 \%(7 / 36)$ of the respondents. Palliative radiotherapy was an option for 36\% (13/36) of the respondents. Supportive care was an option for $47 \%(17 / 36)$ of the respondents.

Combination therapy as well as single agents were options for induction therapy. Docetaxel, Cisplatin and 5FU was the most popular triple agent induction, chosen by $62 \%(22 / 36)$ of the respondents. The most commonly used doublet was Cisplatin and 5FU, an option for 62\% (22/36) of the respondents. Common single agents were Cisplatin and Carboplatin utilised by $36 \%(13 / 36)$ and $28 \%(10 / 36)$, respectively. Two (5.6\%) of the physicians did not use induction chemotherapy.

The most common agent used in chemoradiation therapy was Cisplatin. It is an option when given 3-weekly for $56 \%$ $(18 / 22)$ and weekly for $50 \%(16 / 32)$ of the respondents. 
Carboplatinum as a 3-weekly option was chosen by $28 \%$ (9/32). Carboplatin is a weekly option $41 \%(13 / 32)$. Thirtyone per cent chose doublet therapy with Cisplatin and 5FU. Nineteen per cent (6/32) listed Cetuximab as an option for concurrent therapy.

Cisplatin and 5FU was the most popular therapeutic option for $64 \%(21 / 33)$ of the respondents in the management of patients with recurrent, irresectable or metastatic disease. This was followed by single agent Cisplatin for 58\% (19/33) and Carboplatin for $46 \%(15 / 33)$ of the respondents. Cetuximab was an option as sole therapy for $15 \%(5 / 33)$ or as combination therapy for $18 \%(6 / 33)$ of the respondents in this setting.

\section{Radiotherapy facilities}

Fifty-eight per cent (19/33) of the respondents have access to multiple energy linear accelerators. This was followed by Cobalt, which was available to $46 \%(15 / 33)$ of the respondents. Single energy linear accelerators were used by $18 \%(6 / 33)$ of the respondents. Three per cent reported no radiotherapy facilities available.

Forty-five per cent $(13 / 29)$ of the respondents do not have access to brachytherapy. High dose rate is utilised by $38 \%$ $(11 / 29)$ of the respondents. Low dose rate brachytherapy is available to $17 \%(5 / 29)$ of the respondents. Sixty-six per cent of the respondents $(21 / 32)$ have access to $3 \mathrm{D}$ conformal radiotherapy. Two-dimensional radiotherapy and clinical mark-up were utilised by $47 \%(15 / 32)$ and $34 \%(11 / 32)$ of the respondents, respectively. Twenty-two per cent of the respondents $(7 / 32)$ had access to intensity modulated radiotherapy.

\section{Palliative care}

Seventy-eight per cent $(28 / 36)$ of the respondents had access to oral morphine. Forty-two per cent $(15 / 36)$ has access to hospice care. Twenty-five per cent $(9 / 36)$ of the respondents had access to home-based care.

\section{Conclusion}

In the author's opinion, the survey highlights some of the relevant obstacles encountered in the diagnosis and management of head and neck cancer. It is limited by the number of respondents. This is partly attributed to the small numbers of medical professionals working in this field in Africa. Most respondents are South African, which skews the results. Also, physicians with reliable access to the internet are more likely to respond. The initial part of the survey records the lack of resources required for diagnosis and staging. The high proportion of respondents that chose palliative options for early, curable disease is concerning. This is reflected in the management options chosen. Surgery and adjuvant radiotherapy are important modalities of therapy for locally advanced tumours. This contrasts with the developed world where organ preservation with chemoradiation is the preferred modality of therapy.
Induction chemotherapy was used by a significant proportion of the respondents. It is often used as a temporising measure, owing to the long waiting lists for chemoradiation. It is an indicator of the bulk of disease at presentation. It is often utilised to shrink tumours away from dose limiting organs at risk. Induction chemotherapy followed by chemoradiation is a necessary management option in patients with inoperable, locally advanced tumours in the developed world. This option is only available to centres that have oncological and ancillary services available. The infrastructure for this complex 'package of care' is mandatory. Thoughtless adherence to published management guidelines will not yield equivalent outcomes. ${ }^{9}$

The role of induction chemotherapy has not been clarified for head and neck cancer. Many of the studies looking at this issue were underpowered and could not show an overall survival benefit. ${ }^{10}$ It has also been reported that the toxicity associated with induction chemotherapy does not justify its utilisation. ${ }^{11}$ Taking all these factors into account, organ preservation for operable tumours with induction chemotherapy and/or chemoradiation is not a viable option in most developing countries. This is apparent by the significant role played by surgery, as reported by the respondents. Management must be appropriate to the local context. Is it ethical to offer organ preservation when the resources for salvage procedures are lacking? ${ }^{12}$

The substantial percentage of patients, with curable disease that are treated palliatively requires action. It is imperative that increased investments in diagnostics, surgery, chemotherapy, radiotherapy and ancillary services are motivated for by governments or funders. The rational use of limited resources cannot be overemphasised. The role played by multidisciplinary teams in guiding the rational use of resources is documented in the literature. ${ }^{13,14}$ The composition of the team will be guided by resources. The implementation of appropriate, standardised protocols will allow outcomes to be ascertained and inform future, relevant guidelines. The multidisciplinary clinic is a source of support for physicians working in a resource-constrained environment. It is challenging to decide on the allocation of resources on your own. The deplorable access to morphine and palliative care services compounds the suboptimal management in developing countries. The need for palliative care services and education is paramount.

The proportion of patients with HPV-positive disease is hard to estimate, as many centres do not have access to routine testing. The prevalence of HPV-positive disease in sub-Saharan Africa is not known. It has been hypothesised that the HPV pandemic will still emerge in developing countries owing to their burden of sexually transmitted infectious diseases. ${ }^{15}$ Access to this information may allow prognostication and the informed allocation of resources.

Poor access to multidisciplinary teams highlights the need for African education programmes to develop services in the 
African continent. There are independent programmes in place for the development of head and neck surgeons, oncologists, pathologists, radiotherapists and radiologists. 16,17,18,19 Concerted coordination between these independent entities to train staff who will return to the same centres to start multidisciplinary teams is required. Centres are more likely to retain staff, if they can work in a supportive team. Trainers from the developed world are needed to support and develop infrastructure. Governments and funders may be more inclined to provide infrastructure to a coordinated programme. Professional oncology societies have a duty to assist in the development of services on the African continent.

\section{Acknowledgements Competing interests}

The author declares that she has no financial or personal relationships that may have inappropriately influenced her in writing this article.

\section{References}

1. Halperin EC, Perez CA, Brady LW. Perez and Brady's principles and practice of radiation oncology. Philadelphia, PA: Lippincott Williams \& Wilkins; 2008.

2. Pfister DG. NCCN guidelines head and neck cancers, in NCCN physician guidelines [homepage on the Internet]. 2018 [cited 2018 Sep 11]; p. 1-187. Available from: https://www.nccn.org/store/login/login.aspx?ReturnURL=https://www.nccn. org/professionals/physician_gls/pdf/head-and-neck.pdf.

3. Nibu K-I, Hayashi R, Asakage T, et al. Japanese clinical practice guideline for head and neck cancer. Auris Nasus Larynx. 2017;44(4):375-380. https://doi. org/10.1016/j.anl.2017.02.004

4. Grégoire V, Lefebvre JL, Licitra L, Felip E; EHNS-ESMO-ESTRO Guidelines Working Group. Squamous cell carcinoma of the head and neck: EHNS-ESMO-ESTRO Clinical Practice Guidelines for diagnosis, treatment and follow-up. Ann Oncol. 2010;21(suppl 5):v184-v186. https://doi.org/10.1093/annonc/mdq185

5. D'cruz A, Lin T, Anand AK, et al. Consensus recommendations for management of head and neck cancer in Asian countries: A review of international guidelines. Ora Oncol. 2013;49(9):872-877. https://doi.org/10.1016/j.oraloncology.2013.05.010
6. Morhason-Bello IO, Odedina F, Rebbeck TR, et al. Challenges and opportunities in cancer control in Africa: A perspective from the African Organisation for Research and Training in Cancer. Lancet Oncol. 2013;14(4):e142-e151. https:// Research and Training in Cancer. Lancet
doi.org/10.1016/S1470-2045(12)70482-5

7. Chukwuneke FN, Ezisi C, Anyanechi C. Late presentation and synopsis of inoperable cancer of the head and neck region in Enugu, South-East Nigeria: Our experience. Int J Oral Maxillofac Surg. 2011;40(10):1163. https://doi. org/10.1016/j.jiom.2011.07.464

8. Kingham TP, Alatise OI, Vanderpuye $\mathrm{V}$, et al. Treatment of cancer in sub-Saharan Africa. Lancet Oncol. 2013;14(4):e158-e167. https://doi.org/10.1016/S14702045(12)70472-2

9. Fagan J, Stannard CES, Dalvie S. Open access atlas of otolaryngology, head \& neck operative surgery [homepage on the Internet]. 2014 [cited 2018 Nov 27]. Available from: https://vula.uct.ac.za/access/content/group/ba5fb1bd-be9548e5-81be-586fbaeba29d/Management $\% 20$ Principles $\% 20$ Guidelines $\% 20$ for $\% 20 \mathrm{Head} \% 20$ and $\% 20 \mathrm{Neck} \% 20$ Cancer $\% 20 \mathrm{in} \% 20 \mathrm{Developing} \% 20$ Countries.pdf.

10. Budach W, Bölke E, Kammers K, et al. Induction chemotherapy followed by concurrent radio-chemotherapy versus concurrent radio-chemotherapy alone as treatment of locally advanced squamous cell carcinoma of the head and neck (HNSCC): A metaanalysis of randomized trials. Radiother Oncol. 2016;118(2):238-243. https://doi. org/10.1016/j.radonc.2015.10.014

11. Venkatesan P. No role for induction chemotherapy for head and neck cancers Lancet Oncol. 2018;19(10):e510. https://doi.org/10.1016/S1470-2045(18) 30565-5

12. Chaves ALF, Carvalho AL, Sanabria A, Trivedi NP, Ferrigno R, Kowalski LP. Head and neck cancer treatment in a developing country: A survey-based study in Brazil. Cancer Policy. 2017;13:18-23. https://doi.org/10.1016/j.jcpo.2017.05.006

13. Licitra L, Keilholz U, Tahara M, et al. Evaluation of the benefit and use of multidisciplinary teams in the treatment of head and neck cancer. Oral Oncol. 2016;59:73-79. https://doi.org/10.1016/j.oraloncology.2016.06.002

14. Kelly SL, Jackson JE, Hickey BE, Szallasi FG, Bond CA. Multidisciplinary clinic care improves adherence to best practice in head and neck cancer. Am J Otolaryngol. 2013;34(1):57-60. https://doi.org/10.1016/j.amjoto.2012.08.010

15. Raubenheimer E, Slavik T, Lemmer L, Olivier H, Van Heerden WFP, Miniggio H. Human papillomavirus and carcinoma of the mucosal surfaces of the head and neck. J Oral Maxillofac Surg Med Pathol. 2018;30(1):55-59. https://doi. org/10.1016/j.ajoms.2017.08.003

16. Balogun O, Rodin D, Ngwa W, Grover S, Longo J. Challenges and prospects for providing radiation oncology services in Africa. Semin Radiat Oncol. 2017;27(2):184-188. https://doi.org/10.1016/j.semradonc.2016.11.011

17. Fagan JJ. Workforce considerations, training, and diseases in Africa. Otolaryngo Clin North Am. 2018;51(3):643-649. https://doi.org/10.1016/j.otc.2018.01.009

18. Sciences-UCT, f.o.h. New 3D radiotherapy course a major boost for cancer treatment in Africa [homepage on the Internet]. 2015 [cited 2018 Nov 21]. Available from: http://www.health.uct.ac.za/news/new-3d-radiotherapy-coursemajor-boost-cancer-treatment-africa.

19. Fagan JJ, Otiti J, Aswani J, et al. African head and neck fellowships: A model for a sustainable impact on head and neck cancer care in developing countries. Head Neck. In press 2019 